\title{
Measuring prevailing practices of healthcare professional on electronic health record through the lens of Iraq
}

\author{
Murtaja Ali Saare ${ }^{1}$, Alia Ahmed Mahdi ${ }^{2}$, Saima Anwar Lashari ${ }^{3}$, Sari Ali Sari ${ }^{4}$, Norhamreeza Abdul \\ Hamid $^{5}$ \\ ${ }^{1}$ School of Computing, Universiti Utara Malaysia, Kadah, Malaysia \\ ${ }^{2}$ Office of the Inspector General, Directorate of Health, Karbala, Iraq \\ ${ }^{3}$ College of Computing and Informatics, Saudi Electronic University, Dammam, Saudi Arabia \\ ${ }^{4,5}$ Faculty of Computer Science and Information Technology Universiti Tun Hussein, Johor, Malaysia
}

\begin{tabular}{|c|c|}
\hline Article Info & ABSTRACT \\
\hline & \multirow{11}{*}{$\begin{array}{l}\text { Paper based approach to clinical documentation such as handwritten notes } \\
\text { among health care providers are cause of errors in medical field. Therefore, } \\
\text { health record system needs to be replaced with electronic health record } \\
\text { (EHR). Many health professionals in developing countries specifically in } \\
\text { Iraq refuse to use the systems implemented for their benefits due to many } \\
\text { reasons. Thus, the use of electronic services is important for successful } \\
\text { electronic health implementations. Therefore, this study is intended to } \\
\text { identify the main factors affecting the intention of use of the electronic health } \\
\text { record in Iraq. Health professional staff who work in the main hospital in } \\
\text { Dhi-Qar is chosen because this province is the first local province that } \\
\text { implemented many electronic projects. The present study examined use of } \\
\text { user acceptance of technology, based on the technology acceptance model } \\
\text { (TAM). Moreover, the quantitative method approach for data collection } \\
\text { using survey from staff who work in the main hospital in Dhi-Qar. Data was } \\
\text { analyzed using Structural Equation Modeling using AMOS. The results } \\
\text { indicated significant relationship between Ease of Use, Usefulness, } \\
\text { Usefulness, Attitude, and Intention of use of EHR. These finding have } \\
\text { implementation for decision makers in Iraq government to improve future } \\
\text { implementation of e-health services. }\end{array}$} \\
\hline Received Aug 20, 2020 & \\
\hline Revised Nov 16, 2020 & \\
\hline Accepted Dec 11, 2020 & \\
\hline Keywords: & \\
\hline Electronic health & \\
\hline Health & \\
\hline Quantitative approach & \\
\hline SEM & \\
\hline TAM & \\
\hline Workers & \\
\hline
\end{tabular}

This is an open access article under the $\underline{C C B Y-S A}$ license.

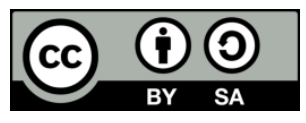

Corresponding Author:

Murtaja Ali Saare

School of Computing

Universiti Utara Malaysia

Sintok, 06010 Bukit Kayu Hitam, Kadah, Malaysia

Email: mmurtaja88@gmail.com

\section{INTRODUCTION}

Electronic health record (HER) is a term that is used to refer to the patients' medical records which are gathered in an electronic format. Hence, these records become portable and accessible at anytime and anywhere. providing an effective solution to the problems and complications faced in the process of health data management [1]. Moreover, it can easily transfer electronic records [2] to different channels at one time. EHR helps to modernize medical as well as the clinical data to be automatically generated and well structured. Therefore, it is believed that this approach may help patients in getting better healthcare and physicians to get up-to-date information. Hence, contributing to effectiveness of medical system.

Most of the data in a hospital are related to the patient are gathered in the form of charts using paper-based record keeping [3], making the records critical to manage and utilize. However, governments of 
developed countries have invested funds in developing the advanced healthcare technology over the last few decades. For instance, US has spent 25.8 to 30.5 billion dollars within between 2007 and 2013 for health informatics. Moreover, European Union (EU) has spent $15 \%$ from their total budget specifically for digitalized healthcare and apart from that, $€ 50$ billion have been allocated by the European Commission to health informatics research within 2007 to 2013 [4]. However, in a developing nation the use of modern technologies in the health sector is still limited [4] the attention to electronic healthcare has been highlight by numerous previous studies but regrettably many developing countries use paper to record the record patient's information.

Paper based record keeping has many disadvantages such as ambiguous, incomplete data, poor availability, and data fragmentation [5]. Hence, this argument is as considered as one of the motivations to conduct this study in developing countries, such as Iraq. Previous researcher also argued that, there is a state of realization that the users' acceptance in technology that is apparently lacking has contributed towards the loss of resources as well as money. Moreover, Hanafizadeh [6] also added that assessment of willingness to adopt is crucial for the success of EHR in developing nations. Hence, to enhance the acceptance of the electronic health records among the health professionals, the present study attempts in determining the key factors influencing the intention of use [7] of this phenomenon in the hospitals available in Iraq.

\section{CONCEPTUAL MODEL}

The present study utilized the technology acceptance model to evaluate the factors that lead to end users adoptoption or technology rejection. Morever, this model was developed to be specially usable in the healthcare information technology domain due to it concentrate on two foctors that influence the use of healthcare information technology [8]. Perceived usefulness is the factor that indicates the degree to which a person thinks that information system will help them in the doing their work. Perceived ease of use is the second factor, that is used to indicate how difficult the system would be to use [8]. These factors are based on the theory of reasoned action [8]. It is noted that the user behavioral intention (BI) is determined by the user attitude as well as subjective norm (SN). The objective of the current study is to determine whether gender, age, and IT competency affect technology acceptance model (TAM) [9]. However, TAM was used in several studies in cooperation with a wider range of information technologies, the review of previous researches show that there are very few studies in the healthcare domain and especially in healthcare information technology [10]. Moreover, there were no studies that were found to examine healthcare information administrators and their part in the performance of HER. The conceptual model as shown in Figure 1.

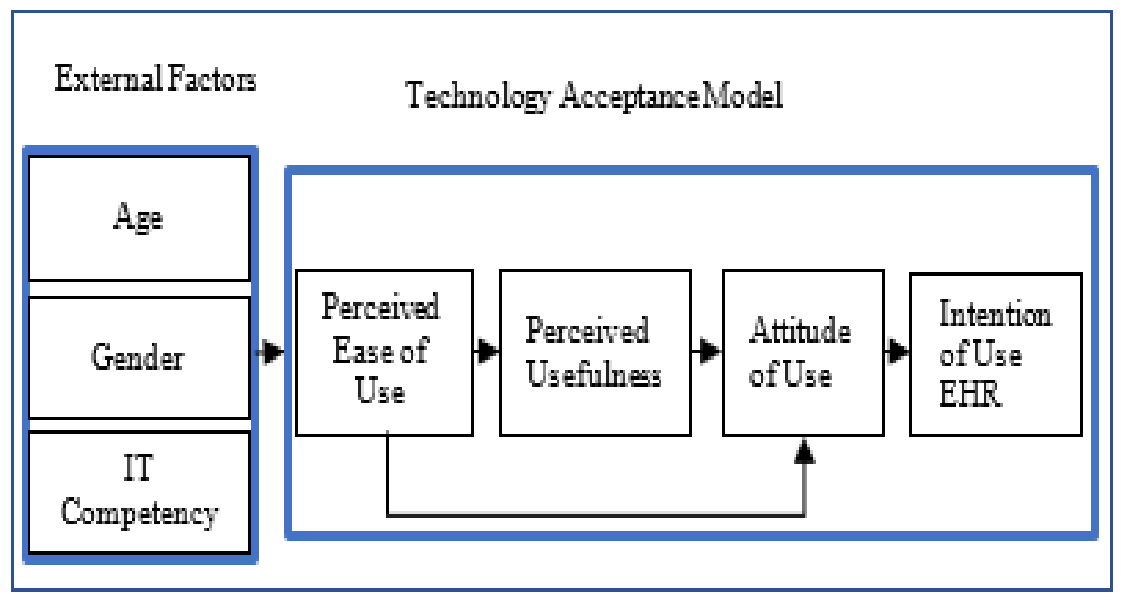

Figure 1. Conceptual model

Previous study found that the demographic factors (such as age, gender and IT competency) were found to have important influence on an individual's intention of usage of technology [11]. Moreover, previous researchers debate over the discrimination on the basis of gender, education, age, Its competency, social status, and ethnic minorities. These researchers found that elderly, less educated, females, low socioeconomic class, and less IT competent people do not adopt to Internet-based systems especially in healthcare technology [12]. 


\section{PRESENT STUDY}

The use of technology in various areas in health service can be seen nowadays where medical informatics are focusing on data storing, processing as well as the management of knowledge and information in relation to the healthcare services. EHR outlines the main point of any e-Health system which are rapidly being used in healthcare reports [13]. Moreover, many types of users such as patients, administrators and application developers use the health information systems and however, these people are having confusion and difficulties in developing as well as using these systems [13, 14].

Furthermore, EHR and its intention of use are considered important in terms of research in technology intention of use as well as the medical information. Similarly, information technology has a major strength in assisting medical and healthcare[12] field due to its automation specialty and it is also believed to have the ability to reduce inefficiencies of the traditional method besides lowering the costs of transactions. Nevertheless, the change in the use of papers to the new way of using ERSs require a long process and is quite hard to accomplish as there is a need to satisfy several authorities and stakeholders. It has also been affirmed by [6] that EHR and its assessment of willingness to adopt are crucial for the success of EHR and the e-health in developing nations. Within similar context, claimed that; despite the well documented benefits of the Electronic Health Records (EHR), the development and use of this system in some developing countries [15] was quite challenging and hard to be captured by the users. Based on these theoretical arguments, it will be very useful to investigate the willingness of developing countries to adopt EHR.

Practically, Iraq as a developing country tried to take advantage of advances in information and communications technology to provide safe and high-quality services to the citizens. Dhi-Qar is considered as one of the local provinces sought to implement and adopt modern technologies in the public sector. Regrettably, most of the electronic services initiatives have been neglected or have not been used. Therefore, the literature asserted that the pre-implementation (intention of use) is essential for successful electronic health implementations. Hence, the willingness assessment for EHR becomes more crucial in connection with developing countries such as Iraq because this country faced many challenges i.e. the ongoing displacement of families due to the insecure environment and the increasing number of the wounded between the citizens and the army. Consequently, this study is intended to identify the main factors affecting the intention of use of the EHR in developing countries generally and Iraq in particular. In general, this study will be exploiting the technology acceptance model (TAM) to evaluate users' acceptance of electronic health record system. TAM is one of the most cited models; TAM is deemed appropriated in evaluating the acceptance towards e-Health services.

In attaining the key aim of the present study, the researcher had drawn the following objective:

- To investigate the factors which influences on the intention of use of the electronic health record in the public hospital.

- To identify the key factors affecting the intention of use of the electronic health record in Iraq based on the health professionals' perception.

\section{RELATED WORK}

In the era of globalization and transformation of technology nowadays, challenges started to arise and most of them are in terms of the ageing population and runway healthcare cost. e-health offers the opportunities to both public as well as private healthcare providers [16] in optimizing its services besides upgrading the quality of service and care to patients. e-health is defined as the "use of information and communications technologies (ICT) in support of health and health-related fields, including health-care services, health surveillance, health literature, and health education, knowledge and research".

Moreover, e-health application has its strength in supporting self-management and care. Apart from that, the e-health system is designed and implemented [17] in developing countries and in this context it is usually undertaken with specific expectation i.e. improved quality for satisfaction, continuity of care, improved tracking system of patients' appointment and follow up, improved administrative and treatment programmers, improved safety of patients, enhanced performance clinically and environmentally in terms of workflow of the workers, advanced decision making and last but not least, have the ability to reduce the overall costs and provide a perfect data quality and availably. However, as with all implementations of information and communication technologies, the translation of the benefits theoretically to realized outcomes is apparently difficult to be achieved and the subjects are currently subjected to a variety of factors contextually. Therefore, it comes to a state of realization that; even though the e-health systems i.e. EHR happened to be successfully installed, the utilization of the systems often faced challenges if there are things that are not clear about it and besides that, the outcome can as well limit the potential of these system [18] to appear being reliable and efficient to achieve the desired objective, particular in developing countries. 
Therefore, the assessment in finding the willingness of intention of use the electronic health systems (for instance EHRs) in Iraqi hospitals is aimed to be done based on the health workers to reduce the failure rate. According to [6], the assessment of willingness to adopt electronic health is crucial for the success of electronic health record in developing populace.

\subsection{Electronic health records}

It seems to be easy to receive the wrong medications or even treatment nowadays and this also seems to be crucial especially when access to patients' documentation is not available for physicians. It has also been argued that major problem in the administration will be seen if there is a lack of proper and exact information provided and thus, this will have an impact towards the healthcare service quality and outcomes of the patients themselves. In addition, traditional paper-based clinical documentation methods are being overcome due to various factors such as the efficient information exchange, the financial and legal complications of the modern healthcare setting, medical errors hazard, and increase in biomedical knowledge. Therefore, technological advances are increasing at a rapid pace of information exchange since, EHR system can overcome the limitation of paper-based methods. In general, EHR systems are known as the important technology which is used to ensure several crucial aspects such as safety, quality and efficiency when it comes to healthcare. This EHR is actually presumed as a spotlight of any other systems regarding e-health.

In literature, most of the researchers focused on the EHR system in the developed countries context. Moreover, there is a notable absence in terms of EHR research in developing countries. For instance, a study conducted in USA using a survey with 995 physicians who currently used EHRs. Technology acceptance model was the foundation of this study. The findings of this study indicated that EHR systems utilized by the adopters recently, when compared to the adopter's way earlier, appear to have problems like missing key patient safety besides affecting the cost control functions. There was also another study conducted in USA simply to examine the factors influencing the health information managers in adopting the EHR. Where the researcher used technology acceptance model by distributing the questionnaire among the managers to measure the perceived usefulness (PU), and ease of use (EOU) as factors influencing health information managers who implement EHR.

A study was conducted on the EHR in Canada. This study aimed to have the comparison between the perceptions among physicians on the utilization of EHR and with those who did not utilize it in the working environment [19]. In addition, 220 physicians participated in this study and The Unified Theory of Acceptance and Use of Technology (UTAUT) was apparently adopted for this purpose. The findings had shown that, PEOU was a strong motivator among the EHR users and meanwhile, the PU and PEOU were the determinants for those who are not using EHR. In Spain, an empirical study on EHR was also conducted. Moreover, a research was conducted aimed at examining the acceptance of the physicians towards EHR specifically regarding the intentions of using it within the hospitals in Spain. Quantitative method was used in attaining the objective of this study. More precisely, 254 physicians in private medical practices were employed for this purpose. Theoretically, this particular study used the key factors such as PU, PEOU, attitude towards use and usage intentions extended with trust and not to forget, the risk related factors. Besides that, the relationship between several factors such as PU, PEOU and attitude towards use and intention of use were also analyzed.

\subsection{ICT in Iraq}

It cannot be denied that ICT is an important and it is actually simply because it provides the room for the developing states to achieve the development goals i.e. reducing poverty, basic healthcare and education more effectively that what is expected before. Basically, in Iraq, the situation is turbulent and the governments have the power in improving the telecom sector as well as enhancing the society that is more towards ICT [20] and besides that, they also get involve with the private sectors which was driven from the establishment of the regulatory environment as signified by the Communications and Media Commission, which resulted in a boom in the mobile services. In addition, several electronic initiatives were launched recently i.e. e-portal, Citizen E-Government and information sharing among local agencies and so on. In fact, most of these projects are either partially or completely fail. For instance, it has been found that there were weaknesses when it comes to the process of establishing the e-government applications which promotes the use of online service [21] around Iraq. Moreover, according to United Nations survey in 2014, it has been claimed that the progress in the completion of e-government in Iraq has been slow and recently the rank has been steadily decreasing. Hence, the Iraqi e-government portal has been ranked 134th in the world [22]. Thus, it can be concluded that there are weaknesses in the current Iraqi e-government portal [23].

Based on the empirical study conducted by [23] to measure the satisfaction of citizens toward the Iraqi e-government, $87 \%$ of the respondents are not satisfied with the e-services available in the portal. This 
result reduces the use or acceptance of citizens for any electronic project in future. Therefore, we need more theoretical and empirical research to understand the issues that impede to implement the electronic ventures in countries that is developing in general as well as those which are based in Iraq specifically.

\subsection{Electronic health in Iraq}

Health information systems in Iraq previously were done using paper-based and then it was manually processed as they were having difficulties in terms of the availability of computers, networking system as well as the personnel to maintain and run the system. A few years ago, this issue has been realized by the Ministry of Health especially on the crucial needs of IT specifically in gathering data as well as maintaining the processing part of health information [3]. Consequently, the Ministry of Health then put the effort together in adapting the utilization of modern technology within the context of health facilities and it was being done in the central as well as the provincial levels. However, EHR intention of use in Iraqi hospitals has been limited despite the possible advantages provided by these systems [3, 24, 25]. These arguments are supported by [5] who stated that e-health systems are evenly applicable by both an advanced and developing nations since technologies are now widely available.

However, the implementation of e-health systems in most of the developing countries [9] face users' (doctors) resistance as it is particularly caused by the advancement of the IT applications used in the healthcare world. Basically, the previous reason besides the troubled situation of the projects involving electronics in public hospitals has actually brought to this empirical study in digging out the issues related to this area by the testing on the key factors which happened to influence the acceptance of EHR in public hospitals in Iraq. According to governmental reports, the usage of electronic health systems within public hospitals of Iraq is still low and problematic [3]; therefore, the present study aims at examining the opinions of healthcare staff about the intention of use of e-health in public hospitals of Iraq.

\section{METHOD}

\subsection{Research design}

This study utilized a cross sectional research design as data was collected at one point in time.

\subsection{Participants}

The participants were 200 Doctor and nurse's majority females (67\%) were aged between 25 and 40 whereas males were $33 \%$ who were recruited from Dhi-Qar hospital.

\subsection{Procedure}

After getting permission from hospital administration the data was collected. Details of the study were explained to the participants and they were assured that their identity will not be revealed. The selfreport questionnaire was administered in in 15-20 min in Arabic language.

\section{MEASURES}

All well-established instruments were used in the study to ensure reliability. Intention, Attitude, Ease of use, usefulness, and IT competence were measured using [26] respectively. All items were rated on a 5-point Likert scale ranging from 1 (strongly disagree) to 5 (strongly agree).

\section{RESULTS}

\subsection{Statistical analysis}

Data was analyzed using AMOS v. 23. Prior running the analysis, the data was tested for normality, outliers, and missing data [27]. The results did not reveal multivariate outliers. The proposed model adequacy was tested using standardised coefficients which is obtained by maximum likelihood estimation. Goodness of fit of every path model was evaluated from multiple fit indices [28] such as comparative fit index (CFI), the root mean squared residual (RMSEA), and the standardized root-mean-square test (SRMR) [29]. For CFI, a value greater than .90 indicates a good fit. For SRMR and RMSEA, a value below .05 indicates a good fit [28].

\subsection{Testing the proposed model}

Model adequacy was determined using two models (a) direct effect (b) indirect effect [30]. To test the mediating effects of attitude bias-corrected $95 \%$ confidence intervals were computed, as shown in Figure 2 . To evaluate indicator reliability. 


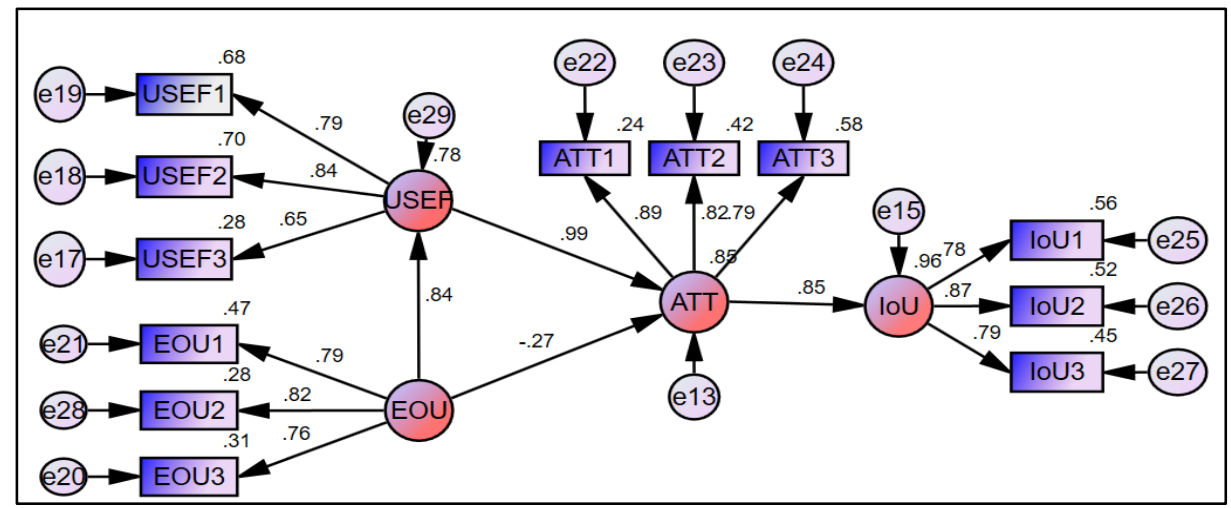

Figure 2. Measurement model

Factors with loadings between 0.4 and 0.7 should be deleted as they are poor indicators of the factors and deleting those would result in an increase in the CR or AVE value[31]. To determine the convergent validity Composite Reliability (CR) and Average Variance Extracted (AVE) tests were carried out. The acceptable range of CR for each construct is 0.70 and above and for AVE is 0.50 and above as suggested by [32]. The present study constructs revealed a satisfactory convergent validity for all the study constructs as shown in Table 1.

Model 1 revealed a good fit to the data $\chi 2(\mathrm{df})=143.42 / 50=2.86, \mathrm{SRMR}=.02, \mathrm{CFI}=.93, \mathrm{RMSEA}=.07$. The structural evaluation of the proposed hypotheses revealed that all relationships were significant expect only one relationship which is between Ease of use to attitude was found insignificant at the t-value was 0.99 . The results also indicated that Ease of use $->$ usefulness, usefulness $->$ attitude has significant influence, and attitude have direct effect on electronic health record intention of use. However, demographic variables such as gender, age, and IT experience were found to have no effect on the intention of use of electronic health record.

Table 1. Discriminant validity of the variable constructs

\begin{tabular}{ccccc}
\hline Latent Variables & 1 & 2 & 3 & 4 \\
\hline Intention of use & 0.81 & & & \\
Attitude & 0.81 & 0.83 & & \\
Ease to use & 0.66 & 0.56 & 0.84 & \\
Usefulness & 0.79 & 0.76 & 0.79 & 0.87 \\
\hline
\end{tabular}

\section{DISCUSSION}

Understanding the attitudes of technology users is of great significance to the field of health informatics. The successful performance and intention to use healthcare informatics systems depends on users satisfaction and acceptance to the technology. However, looking at the statistics of acceptance by physicians it was found limited which act as a barrier to the implementation of electronic record system in health sector. Therefore, the present study aimed at identifying the potential factors that influence the intention of physicians and nurses to adopt EHR in the province of Dhi-Qar (Iraq). Data was gathered in this study from physicians and nurses who work in the main local hospital in Dhi-Qar, Iraq. The results of the investigation found ease of technology use is significantly related to technology usefulness. Meanwhile, usefulness has a significant relationship with attitude and attitudes also significantly affect users' intention to use HER. While, perceived ease of use was found insignificant factor in affecting the users' attitude towards the use of EHR in Dhi-Qar hospital.

Regardless of its vital contributions, the present study has several limitations. First, small sample size and low response rate therefore, the findings cannot to generalize to wider population. Second, the present study did not take into consideration of all the theoretical constructs and focused only on the constructs on the TAM model. Third, the present study concentrates on the one local hospital in the province have good experience on the ICT. Therefore, in the future work need recruitment more physicians and the nurses within several hospitals. In addition, we need to expand TAM by merging several theoretical constructs from several Models such as TBP theory or IS success model. Thus, we would recommend exploring more empirical quantitative and qualitative research before implementation any electronic initiative in the public sector. 


\section{REFERENCES}

[1] P. A. Silva and F. Nunes, "Preface for the special issue on fun and engaging computing technologies for health," Entertainment Computing, vol. 100, no. 15, pp. 4-42, 2016.

[2] M. Mukred, Z. M. Yusof, U. Asma'Mokhtar, and F. Fauzi, "A framework for electronic records management system adoption in the higher professional education: individual, technological and environmental factors," in $A$ Framework for Electronic Records Management System Adoption, pp. 840-849, 2019.

[3] W. K. H. M. Al-Hadban, K. F. Hashim, and S. A. M. Yusof, "Investigating the Organizational and the Environmental Issues that Influence the Adoption of Healthcare Information Systems in Public Hospitals of Iraq," Computer and Information Science, vol. 9, no. 2, pp. 126-139, 2016.

[4] T. Dimitrovski, P. Ketikidis, L. Lazuras, and P. A. Bath, "Adoption of Electronic Health Records (EHRs): A review of technology acceptance studies," Proceedings of the 16th International Symposium on Health Information Management Research, pp. 1-9, 2013.

[5] S. A. Sari and K. M. Mohamad, "A Review of Graph Theoretic and Weightage Techniques in File Carving," in Journal of Physics: Conference Series, vol. 1529, no. 5, pp. 1-16, 2020.

[6] Q. A. Qureshi, B. Shah, N. Khan, K. Miankhel, and A. Nawaz, "Determining the users' willingness to adopt electronic health records (EHR) in developing countries," Gomal University Journal of Research, vol. 28, no. 2, pp. 140-148, 2012.

[7] M. Mukred and Z. M. Yusof, "Factors influencing the adoption of electronic records management (ERM) for decision making process at higher professional education (HPE)'s institutions," in 1st ICRIL-International Conference on Innovation in Science and Technology (IICIST 2015), Kuala Lumpur, pp. 399-403, 2015.

[8] F. D. Davis, "Perceived usefulness, perceived ease of use, and user acceptance of information technology," MIS Quarterly, vol. 13, no. 3, pp. 319-340, 1989.

[9] M. A. Saare, A. Hussain, and W. S. Yue, "Conceptualizing mobile health application use intention and adoption among Iraqian older adults: from the perspective of expanded technology acceptance model," International Journal of Interactive Mobile Technologies, vol. 13, no. 10, pp. 28-41, 2019.

[10] M. A. Saare, A. Bin Hussain, O. M. Jasim, and A. A. Mahdi, "Usability Evaluation of Mobile Tracking Applications: A Systematic Review,” International Journal of Interactive Mobile Technologies, vol. 14, no. 5, pp. 119-128, 2020.

[11] T. Turja, I. Aaltonen, S. Taipale, and A. Oksanen, "Robot acceptance model for care (RAM-care): a principled approach to the intention to use care robots," Information \& Management, vol. 57, no. 5, p. 103220, 2020.

[12] M. A. Saare, A. Hussain, and W. S. Yue, "Relationships between the Older Adult's Cognitive Decline and Quality of Life: The Mediating Role of the Assistive Mobile Health Applications," International Journal of Interactive Mobile Technologies, vol. 13, no. 10, pp. 42-55, 2019.

[13] O. M. Kök, N. Basoglu, and T. U. Daim, Daria Spatar, "Adoption Factors of Electronic Health Record Systems," in Technology in Society, Elsevier, p. 101144, Augst 2019

[14] M. A. Al-Shareeda, M. Anbar, S. Manickam and A. A. Yassin, "VPPCS: VANET-Based Privacy-Preserving Communication Scheme," in IEEE Access, vol. 8, pp. 150914-150928, 2020, doi: 10.1109/ACCESS.2020.3017018.

[15] S. M. M. Muaadh, Zawiyah M. Yusof, Umi Asma' Mokhtar, and Fariza Fauzi, "Framework For Electronic Records Management System Adoption In The Higher Professional Education : Individual, Technological and Environmental Factors," A Framework for Electronic Records Management System Adoption, pp. 840-849, 2019.

[16] J. M. Beer et al., "A Focus Group Evaluation of Breathe Easier: A Mindfulness-Based mHealth App for Survivors of Lung Cancer and Their Family Members," American Journal of Health Promotion, p. 0890117120924176, 2020.

[17] P. A. Silva and A. D. Daniel, "Training Non-designers in Co-design Methods Through an Active Assisted Living Interactive Workshop," in IFIP Conference on Human-Computer Interaction, pp. 166-175, 2019.

[18] K. Gerling et al., "Potential and Limitations of Playful Technology to Support Infant Feeding," in Proceedings of the 2018 Annual Symposium on Computer-Human Interaction in Play Companion Extended Abstracts, pp. 431437, 2018.

[19] N. McDonald, T. C. Callari, D. Bfaranzini, and F. Mattei, "A Mindful Governance model for ultra-safe organisations," Safety Science, vol. 120, pp. 753-763, 2019.

[20] M. Mukred, Z. M. Yusof and F. M. Alotaibi, "Ensuring the Productivity of Higher Learning Institutions Through Electronic Records Management System (ERMS),” in IEEE Access, vol. 7, pp. 97343-97364, 2019.

[21] M. K. Wolters, S. Li, H. Wang, X. Yang, and Y. Guo, "Does the Presence of Privacy Relevant Information Affect App Market Choice?," in Extended Abstracts of the 2020 CHI Conference on Human Factors in Computing Systems, pp. 1-7, 2020.

[22] N. G. Elbahnasawy, "E-government, internet adoption, and corruption: an empirical investigation," World Development, vol. 57, pp. 114-126, May 2014.

[23] A. Hussain, M. A. Saare, O. M. Jasim, and A. A. Mahdi, "A Heuristic Evaluation of Iraq E-Portal," Journal of Telecommunication Electronic and Computer Engineering, vol. 10, no. 1-10, pp. 103-107, 2018.

[24] M. A. Al-Shareeda, M. Anbar, I. H. Hasbullah, S. Manickam and S. M. Hanshi, "Efficient Conditional Privacy Preservation With Mutual Authentication in Vehicular Ad Hoc Networks," in IEEE Access, vol. 8, pp. 144957$144968,2020$.

[25] M. Al Shareeda, A. Khalil, and W. Fahs, "Realistic heterogeneous genetic-based RSU placement solution for V2I networks.," The International Arab Journal of Information Technology, vol. 16, no. 3A, pp. 540-547, 2019.

[26] L. Liu and Q. Ma, "Perceived system performance: a test of an extended technology acceptance model," The DATA BASE for Advances in Information Systems - Spring-Summer, vol. 37, no. 2 \& 3, pp. 51-59, 2006. 
[27] S. A. Lashari, A. Kaur, and R. Awang-Hashim, "Home Away from Home--The Role of Social Support for International Students' Adjustment," Malaysian Journal of Learning and Instruction, vol. 15, no. 2, pp. 33-54, 2018.

[28] P. M. Bentler, "On tests and indices for evaluating structural models," Personality and Individual Differences, vol. 42, no. 5, pp. 825-829, May 2007.

[29] D. Bergh, "Chi-Squared Test of Fit and Sample Size-A Comparison between a Random Sample Approach and a Chi-Square Value Adjustment Method," Journal of applied measurement, vol. 16, no. 2, pp. 204-217, 2015.

[30] S. Lashari, "Environmental and personal factors as predictors of marital adjustment-an investigation in pakistani context," Proceeding of The ICECRS, vol. 1, pp. 991-1002, 2017.

[31] J. F. Hair Jr, G. T. M. Hult, C. Ringle, and M. Sarstedt, "A primer on partial least squares structural equation modeling (PLS-SEM)," Sage Publications, 2016.

[32] C. Fornell and D. F. Larcker, "Structural equation models with unobservable variables and measurement error: Algebra and statistics," Journal of Marketing Research, pp. 382-388, 1981.

\section{BIOGRAPHIES OF AUTHORS}

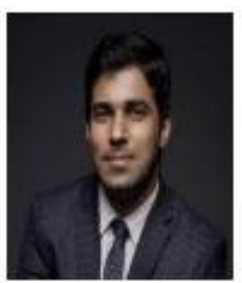

Murtaja Ali Saare is a Ph.D candidate at School of Computing, Sintok, Universiti Utara Malaysia, Kedah, Malaysia. He holds a master's degree in computer science. His research interest includes aging and cognition, e-health and Human-Centered Computing. He has published his research work inreputablescopus indexed journals.

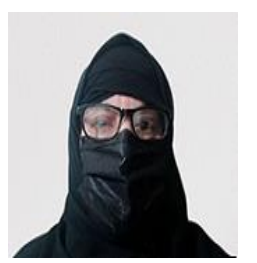

Alia Ahmed Mahdi is a staff at office of the Inspector General, Directorate of Health, karbala, Iraq. She holds a master's degree in information technology. Her research interest includes, egoverment and healthcare.

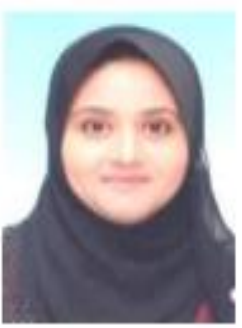

Saima Anwar Lashari obtained her bachelor of science (Hons) in computer science in 2004 at University Of Engineering \& Technology (UET), Lahore, Pakistan. She holds MSc degree in information technology in 2012 at UniversitiTun Hussein Onn Malaysia (UTHM), Malaysia. She completed her PhD in information technology at UniversitiTun Hussein Onn Malaysia (UTHM), Malaysia. Her research interest includes data mining, classification and soft set.

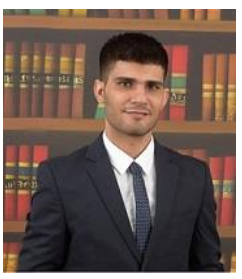

Sari Ali Sari is a Ph.D candidate at UniversitiTun Hussein Onn Malaysia (UTHM), Malaysia. He holds a master's degree in computer science (internetworking technology) at Universiti Teknikal Malaysia Melaka (UTeM). His research interest includes Artificial Intelligence, Network Security, Digital Forensics and Human-Centered Computing.

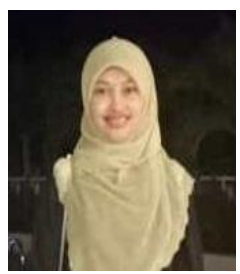

Norhamreeza Abdul Hamid is a Ph.D candidates at Universiti Tun Hussein Onn Malaysia (UTHM). She holds a master's degree in Information Technology (by Research). Her research interests includes Artificial Neural Networks, Data Mining, Artifical Intelligence, Soft Computing and Classification. 